\title{
A DAMAGE LOCALISATION PROCEDURE FOR MASONRY TOWERS BASED ON FREQUENCY DATA
}

\author{
Paolo Borlenghi ${ }^{1}$, Carmelo Gentile ${ }^{1}$, and Antonella Saisi ${ }^{1}$ \\ ${ }^{1}$ Department of Architecture, Built environment and Construction engineering (DABC) \\ Politecnico di Milano, Milan, Italy \\ Piazza Leonardo da Vinci, 32 - 20133 Milan, Italy \\ e-mail: \{paolo.borlenghi, carmelo.gentile, antonella.saisi\}@polimi.it
}

Keywords: Masonry tower, Damage localization, Model updating, Operational Modal Analysis, Non-destructive test, Historical constructions

\begin{abstract}
The structural health conditions of masonry towers can be monitored with a few dynamic sensors (e.g. accelerometers or seismometers) placed at the top of the structure. This cost-effective setup provides continuous and reliable information on the natural frequencies of the structure; however, to move from anomaly detection to localisation with such a simplified distribution of sensors, a calibrated numerical model is needed. The paper summarises the development of a Structural Health Monitoring (SHM) procedure for the model-based damage localisation in masonry towers using frequency data. The proposed methodology involves the subsequent steps: (i) preliminary analysis including geometric survey and Ambient Vibration Tests (AVTs); (ii) FE modelling and updating based on the identified modal parameters; (iii) creation of a Damage Location Reference Matrix (DLRM) from numerically simulated damage scenarios; (iv) detection of the onset of damage from the continuous monitoring system performed with state-of-art techniques, and (v) localisation of the anomalies through the comparison between the experimentally identified variations of natural frequencies and the above-defined location matrix, called DLRM. The proposed SHM methodology is exemplified on the ancient masonry tower of Zuccaro in Mantua, Italy. Pseudo-experimental monitoring data were generated and employed to assess the reliability of the adopted algorithm in identifying the damage location. The results show a promise toward the practical applications of the proposed methodology in the monitoring of real structures.
\end{abstract}




\section{INTRODUCTION}

Within the context of Structural Health Monitoring (SHM) of masonry towers, recent experiences [1-4] provided the evidence that the installation of few high-sensitive accelerometers at the top of the structure, combined with automated modal identification tools, can reveal the onset of damage under changing environments. This cost-effective measurement setup provides continuous and reliable information on the natural frequencies of the structure; however, to move from anomaly detection to localisation with such a simplified distribution of sensors, a calibrated numerical model is needed.

One possibility for performing damage localisation of masonry towers is the use of the surrogate-based FE model updating based on cleaned observations [3]. Once the fluctuations from the environmental effects are removed from the identified natural frequencies, the FE model of the structure is updated each time a new observation is available. Consequently, abnormal changes in structural parameters are detected and correlated with their location; in this case, the localisation is performed among the areas involved in the updating. Another way to localise the damage, based on nonlinear dynamic analysis, is shown in [4]: once an anomaly is detected from the monitoring system, a non-linear dynamic analysis is performed with the recorded seismic sequence to identify the areas prone to damage. Subsequently, the frequency decays obtained from the FE analysis, and the one from the monitoring system are compared. The main limitation of the first approach is the detail of the localisation. At the same time, in the latter, the non-linear dynamic analysis is computationally expensive and based on numerous assumptions on material properties.

In the present study, a model-based damage localisation procedure based on previously computed damage scenarios is developed, to increase the capability of real-time damage evaluation after a seismic event. A FE model of the structure is employed to study how damage in a specific location affects the mutual variation between the natural frequencies; accordingly, a damage localisation algorithm based on natural frequency changes is proposed.

The procedure outlined in this paper is summarised in Fig. 1 and involves the following steps: (i) preliminary analysis including geometric survey and ambient vibration tests (AVTs); (ii) FE modelling and updating based on the identified modal parameters; (iii) creation of a Damage Location Reference Matrix (DLRM) from numerically simulated damage scenarios; (iv) detection of the onset of damage from the continuous monitoring system performed with state-of-art techniques, and (v) localisation of the anomalies through the comparison between the experimentally identified variations of natural frequencies and the DLRM location matrix.

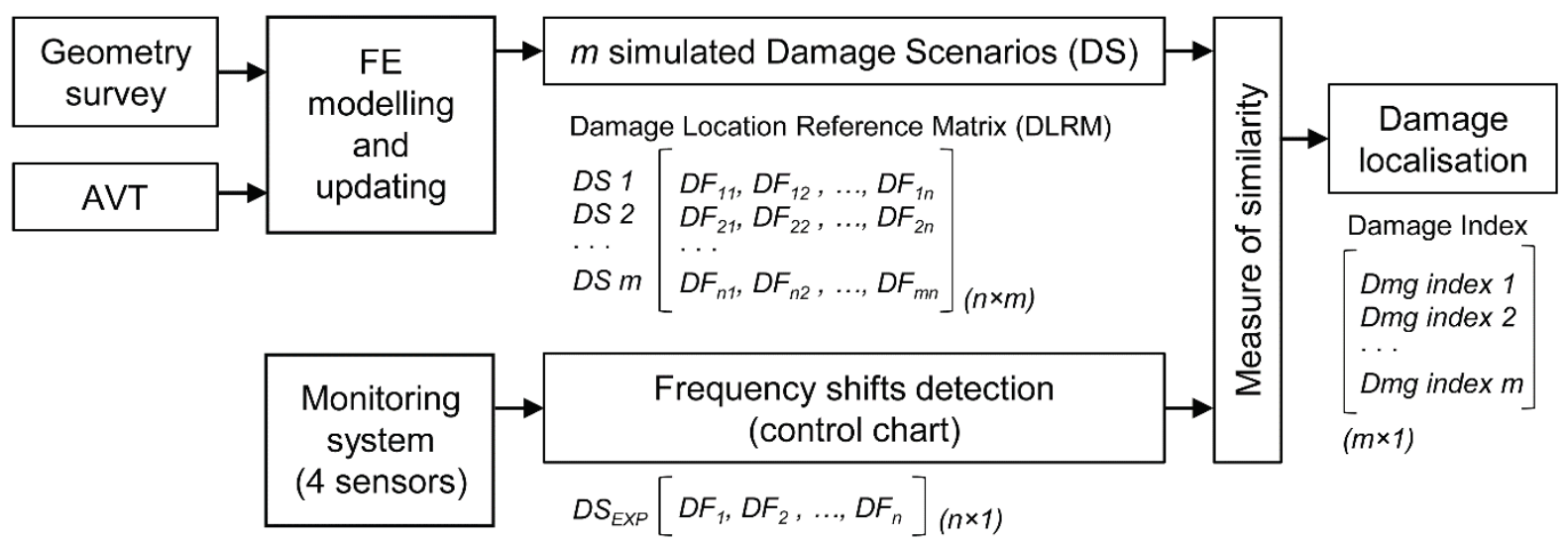

Figure 1: Damage localisation procedure for masonry towers based on the Damage Location Reference Matrix. 
The proposed SHM methodology is exemplified on the ancient Zuccaro's tower in Mantua, Italy. Firstly, documentary research, direct on-site inspections, AVTs and FE modelling and updating were performed and are fully reported in [5] and [6]. Subsequently, pseudoexperimental monitoring data are generated from the calibrated model and employed to assess the reliability of the adopted algorithm in identifying the damage location. It is worth mentioning that the investigated structure is of interest due to the quite large number of identified natural frequencies with only four seismometers and the peculiar shape of the last two modes representing a warping distortion of the cross-section.

\section{THE DLRM APPROACH FOR DAMAGE LOCALIZATION}

The developed DLRM approach is designed to give information on the damage location using only the measured changes in natural frequencies.

It is assumed that a monitoring system with few sensors is available so that the natural frequencies are continuously identified, the environmental effects are removed, and the occurrence of structural anomalies is detected through statistical tools, such as the control charts. Control charts are graphical representations of the evolution over time of a certain process with designed control limits to detect abnormal observations. For SHM purposes, the control limits are based on an initial training period when the structure is assumed to be undamaged. The successful use of control charts in damage detection of ancient constructions has been reported by different scholars $[1,4]$. In this paper, the Hotelling multivariate control chart based on the $\mathrm{T}^{2}$ statistic [7] is adopted.

From a calibrated numerical model, a series of damage scenarios are simulated, and the consequent variations of natural frequencies are collected in a matrix called DLRM. Through a comparison of similarity between the frequency variations in the DLRM and the ones detected from the cleaned observations of the continuous monitoring system, it is possible to locate in which area the anomaly appeared.

To clarify the working principles of the DLRM approach, the model of an idealised masonry tower is employed. Fig. 2 shows the geometry adopted and the $n$ vibration modes involved. As demonstrated by different researches [1-4], the first torsion mode $\left(\mathrm{T}_{1}\right)$ and four bending modes (B) are often identified with the low-cost monitoring setup.

(a)

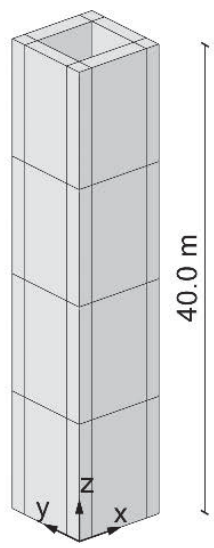

(b)

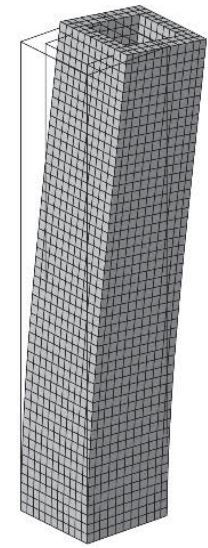

$\mathrm{B}_{\mathrm{x} 1}$ (c)

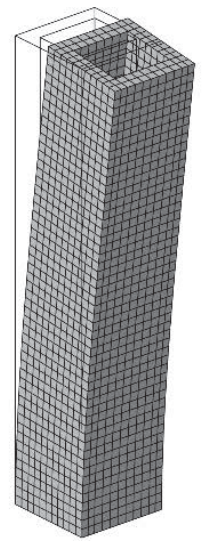

$\mathrm{B}_{\mathrm{y} 1}$

$f_{\mathrm{FEM}}=1.17 \mathrm{~Hz} \quad f_{\mathrm{FEM}}=1.18 \mathrm{~Hz}$

(d)

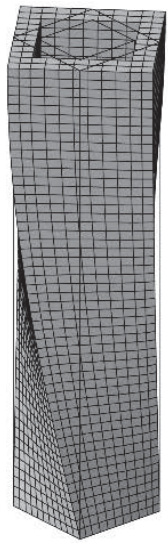

$\mathrm{T}_{1}$ (e)

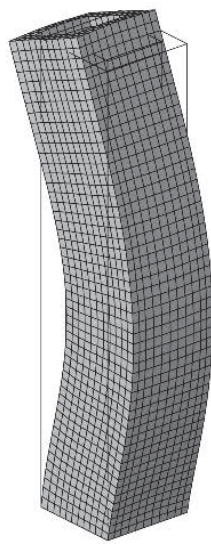

$\mathrm{B}_{\mathrm{y} 2}$

$f_{\mathrm{FEM}}=4.75 \mathrm{~Hz}$

$f_{\mathrm{FEM}}=5.65 \mathrm{~Hz}$ (f)

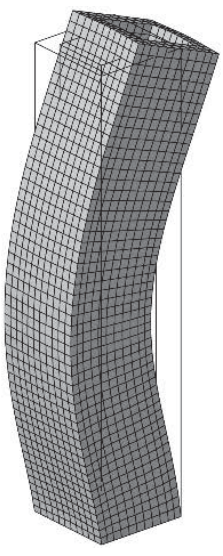

$\mathrm{B}_{\mathrm{x} 2}$

$f_{\mathrm{FEM}}=5.77 \mathrm{~Hz}$

Figure 2: (a) Idealised tower geometry; (b-f) numerical vibration modes employed in the damage localisation. 


\subsection{Creation of the Damage Location Reference Matrix (DLRM)}

The DLRM contains the $m$ percentage of variation of the $n$ considered natural frequencies. The creation of the DLRM is performed as follow:

(i) the previously calibrated FE model is divided into $m$ elements (Fig. 2a), differentiating corners and walls in plan, and floors in height;

(ii) $m$ eigenvalue analyses are performed reducing the elastic modulus of each element by a certain quantity (e.g. 40\%);

(iii) the changes in the $n$ natural frequencies are collected in an $n$-by- $m$ matrix called DLRM.

The effects of the different Damage Scenarios (DSs) are measured through the percentage of frequency discrepancy, defined as follow:

$$
D F_{i}=\frac{f_{i}^{u}-f_{i}^{d}}{f_{i}^{u}} \cdot 100
$$

where the $i$-th natural frequencies of the structure before and after the damage are represented by $f_{i}{ }^{u}$ and $f_{i}{ }^{d}$, respectively.

To give an example on how the location of damage influences the natural frequencies, Fig. 3 illustrates the comparison between the simulated DS of the idealised tower for the elements of two consecutive floors. The DSs are obtained reducing the elastic modulus of each element by the $40 \%$. As presented in Fig. 1, the DSs are the rows of the DLRM.

From the analysis of this simplified application, it is possible to draw the following observations on the effectiveness of the localisation procedure using the frequency variations:

(a) The DS belonging to different floors gives in all cases different pattern of frequency variations (Fig. 3);

(b) The DS of the four corner elements belonging to the same level (Figs. 3a-b, bars with the same colour) gives the same frequency variations;

(c) The DS on the four wall elements belonging to the same floor (Figs. 3c-d, bars with the same colour) gives the same frequency variations when aligned on the same direction.

\subsection{Model-based Damage localisation}

Once the onset of damage is detected, it is possible to identify its location analysing the variation of natural frequencies. Comparing the frequency shifts obtained from the monitoring system with the $m$ simulated damage scenarios, it is possible to locate the damage among the $m$ elements previously identified. The Cosine Similarity is adopted to measure the similarity between the vector of the identified experimental frequency shifts $\left(\boldsymbol{D} \boldsymbol{S}_{E X P}\right)$ and the $m$ vectors of the simulated damage scenarios $\left(\boldsymbol{D} \boldsymbol{S}_{j}\right)$ :

$$
\cos \theta_{j}=\frac{\boldsymbol{D} \boldsymbol{S}_{j} \cdot \boldsymbol{D} \boldsymbol{S}_{E X P}}{\left\|\boldsymbol{D} \boldsymbol{S}_{j}\right\| \cdot\left\|\boldsymbol{D} \boldsymbol{S}_{E X P}\right\|}
$$

where $\theta_{\mathrm{j}}$ is the $j$-th angle between the two vectors. In the present paper, the adopted Damage Index is expressed as follow:

$$
\text { Damage Index }{ }_{j}=\left(\cos \theta_{j}\right)^{2}
$$

where values close to 1 suggest a good correlation with the identified frequency shifts while values lower than 0.8 suggest a poor correlation. The $j$-th Damage Index is then plotted together with the corresponding $j$-th DS - representing the element location - (e.g. Fig. 4). The localisation is then performed considering the location associated with the higher Damage Index. 
(a)
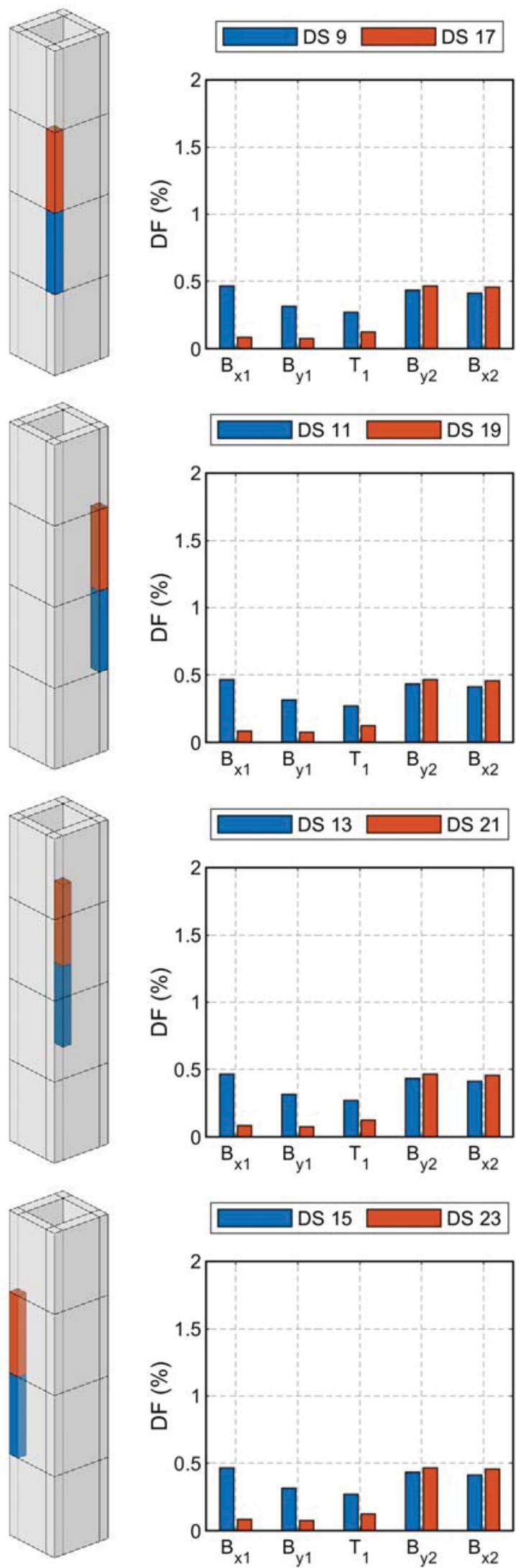

(c)
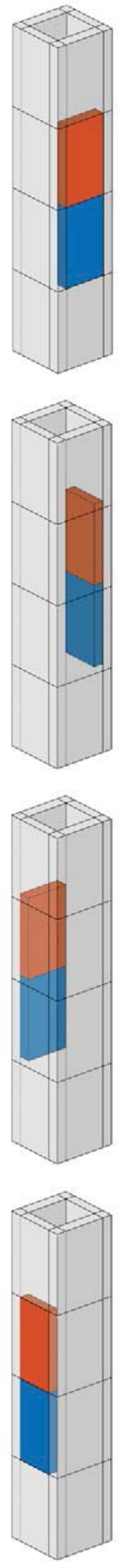

(d)
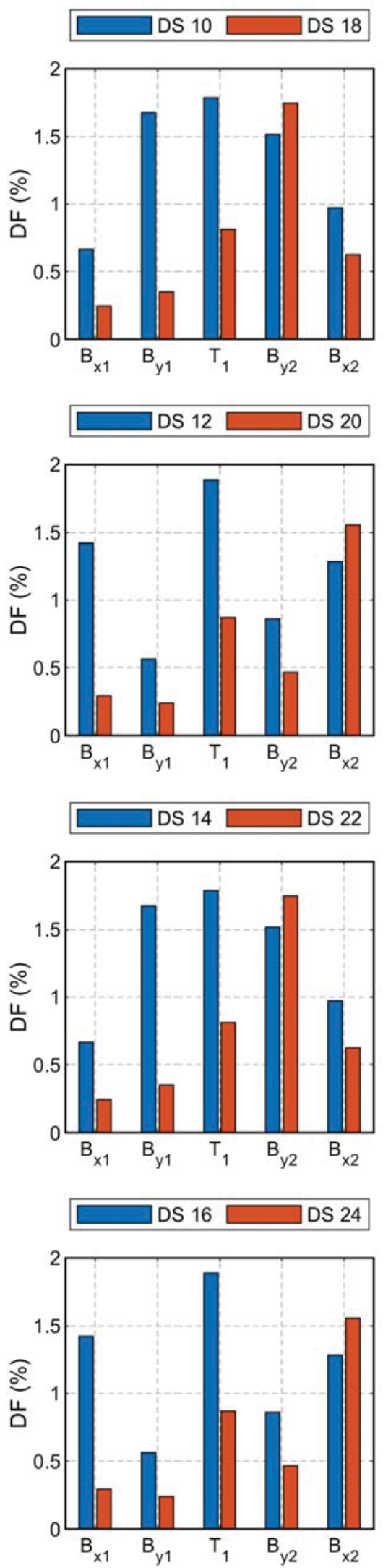

Figure 3: Comparison between the simulated Damage Scenarios (DS) of the first (a-b) and second (c-d) floor in terms of the discrepancy of frequency (DF, Eq. 1). 
(a)
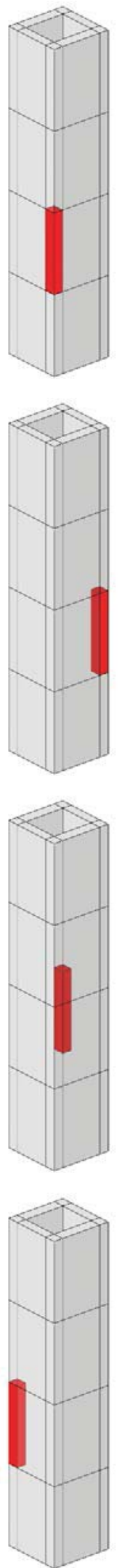

(b)
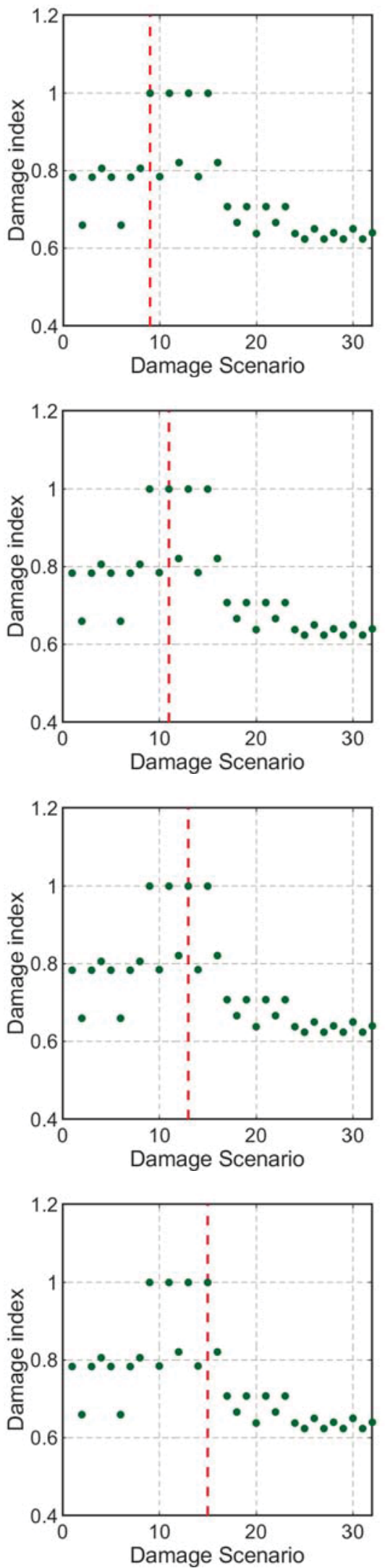

(c)
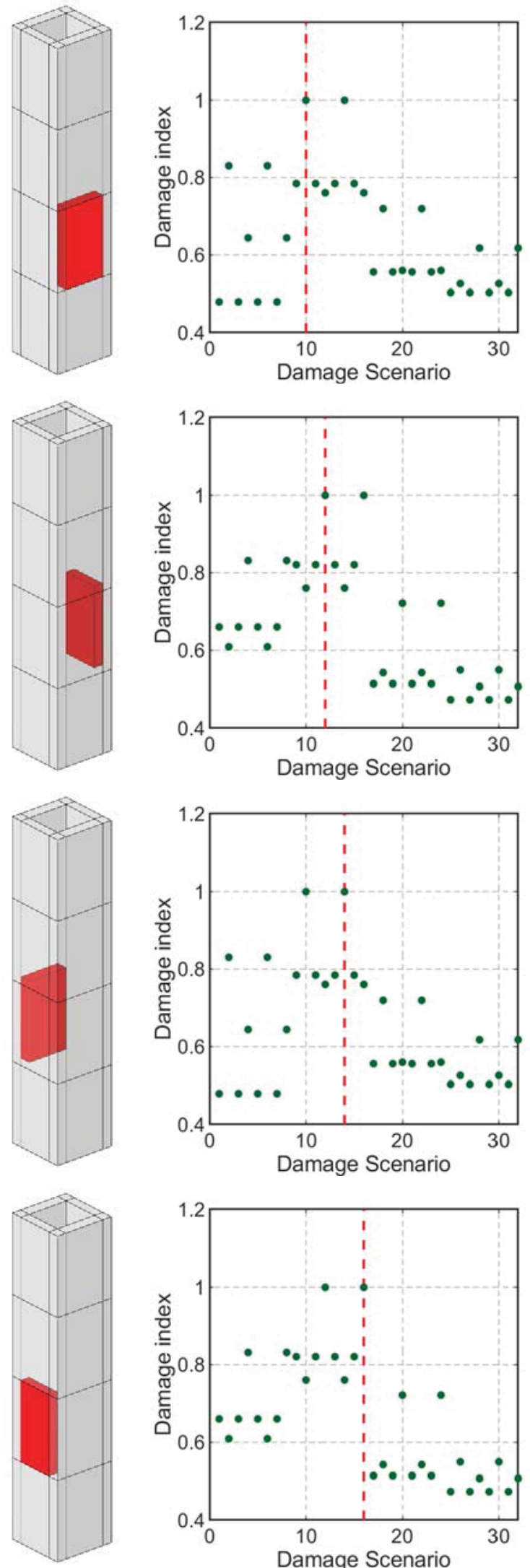

(d)

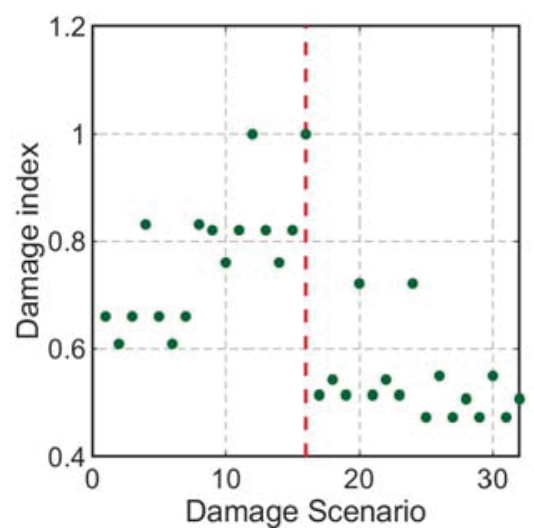

Figure 4: Localisation of simulated frequency shifts obtained by decreasing the elastic moduli of first-floor walls (c-d) and corners (a-b) by the $20 \%$ (the red dashed line represents the actual damage location). 
The localisation procedure is exemplified on the model of the idealised tower. 8 frequency shifts are simulated reducing the elastic modulus of the 8 elements of the first floor by the $20 \%$ (Figs. $4 \mathrm{a}-\mathrm{c}$ ). The simulated $D S_{E X P}$ are then compared with the $j$-th DS of the DLRM. The following observations can be drawn:

(a) As expected, it is not possible to distinguish between a DS on a corner element belonging to the same floor;

(b) Similarly, it is not possible to differentiate between the DS on wall elements belonging to the same level and same direction.

In conclusion, a numerical model of an idealised tower was employed to exemplify the application of the DLRM approach showing promising results. It should be noticed that increasing the number and the type (e.g. bending, torsion, or local) of vibration modes can substantially increase the effectiveness of the localisation capability of the proposed approach.

\section{THE ZUCCARO'S TOWER: DESCRIPTION AND DYNAMIC TESTING}

The Zuccaro's tower of Mantua (Fig. 5), about $43 \mathrm{~m}$ high, is a historical defensive structure built in the Middle Ages [5]. The first record regarding its existence dates back to 1143. The few and small openings and the tower location at the limits of the city Middle Ages fortifications suggest its original defensive role. As shown in Fig. 5, the tower is nowadays included in a building aggregate, surrounded on three-sides by low-rise constructions.

The structure has an approximate squared plan with the side equal to $8.5 \mathrm{~m}$. The loadbearing walls are built in solid brick masonry with a thickness ranging from $1.1 \mathrm{~m}$ at the base to $0.8 \mathrm{~m}$ at the top. A brick masonry cross vault is covering the ground floor, while a timber staircase is connecting the 8 timber floors distributed along the height of the structure (Fig. 7). It is worth mentioning that the roof and the timber floors were substituted after a fire occurred in 1979 and the related intervention - carried out in the 90s - involved the injection of expanding mortars in several areas.

Due to a large number of uncertainties regarding the evolution of the building and the effectiveness of strengthening interventions, an extensive investigation survey was recently carried out involving visual inspection and Ambient Vibration Testing (AVT). The results of the investigations are reported in [5] and [6]. The survey was aimed at providing details on the geometry of the structure, detect critical areas and irregularities, and identify the dynamic characteristics of the structure (i.e. natural frequencies and mode shapes).

(a)

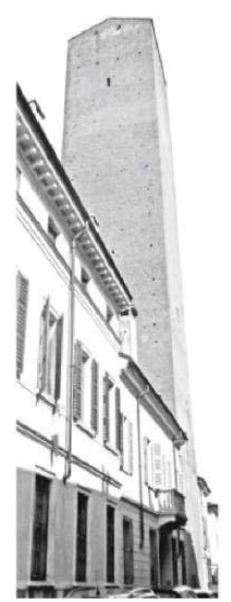

(b)

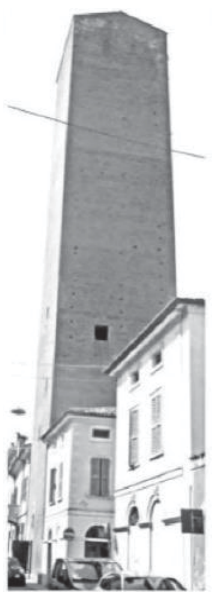

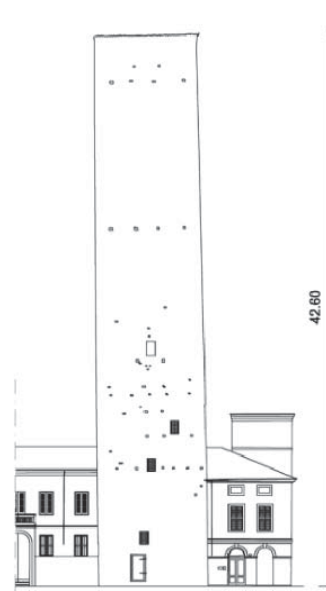

(c)

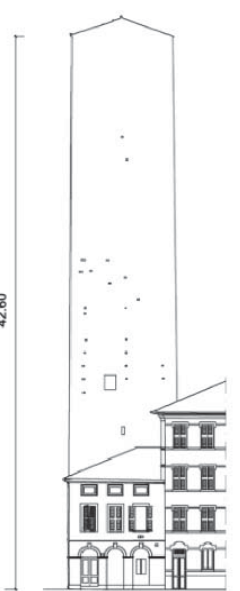

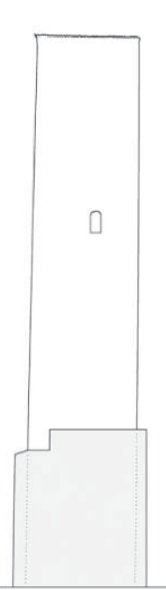

Figure 5: The Zuccaro's tower: views from the west (a) and south corners (b); and geometric survey of the external fronts (c). 
(a)

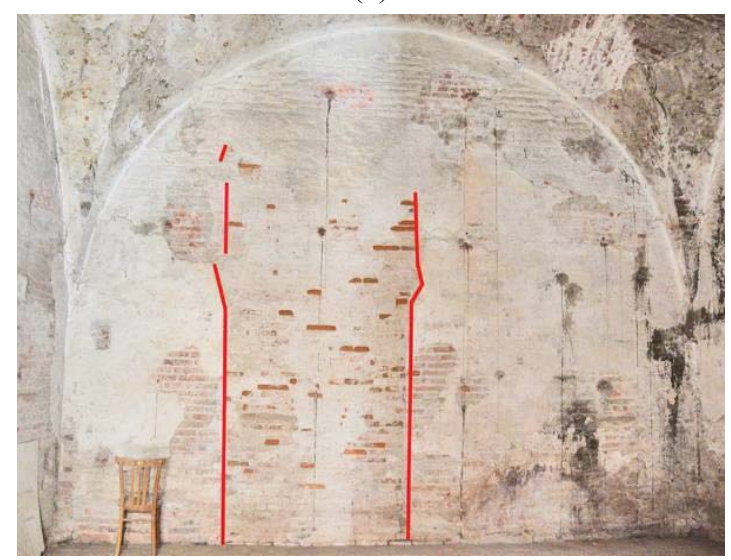

(b)

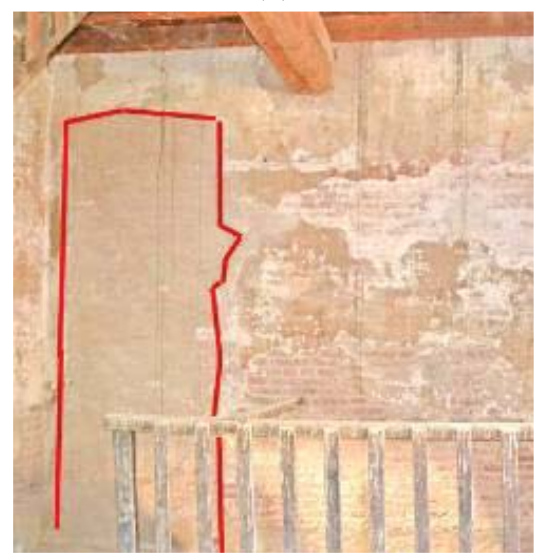

(c)

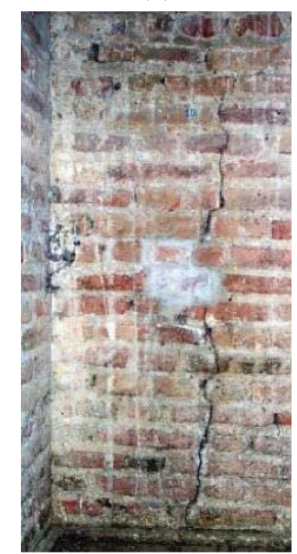

Figure 6: Details of masonry cracks and discontinuities: (a) ground floor, N-E front, (b) 1st floor, S-E front and (c) 3rd floor, S-W front.
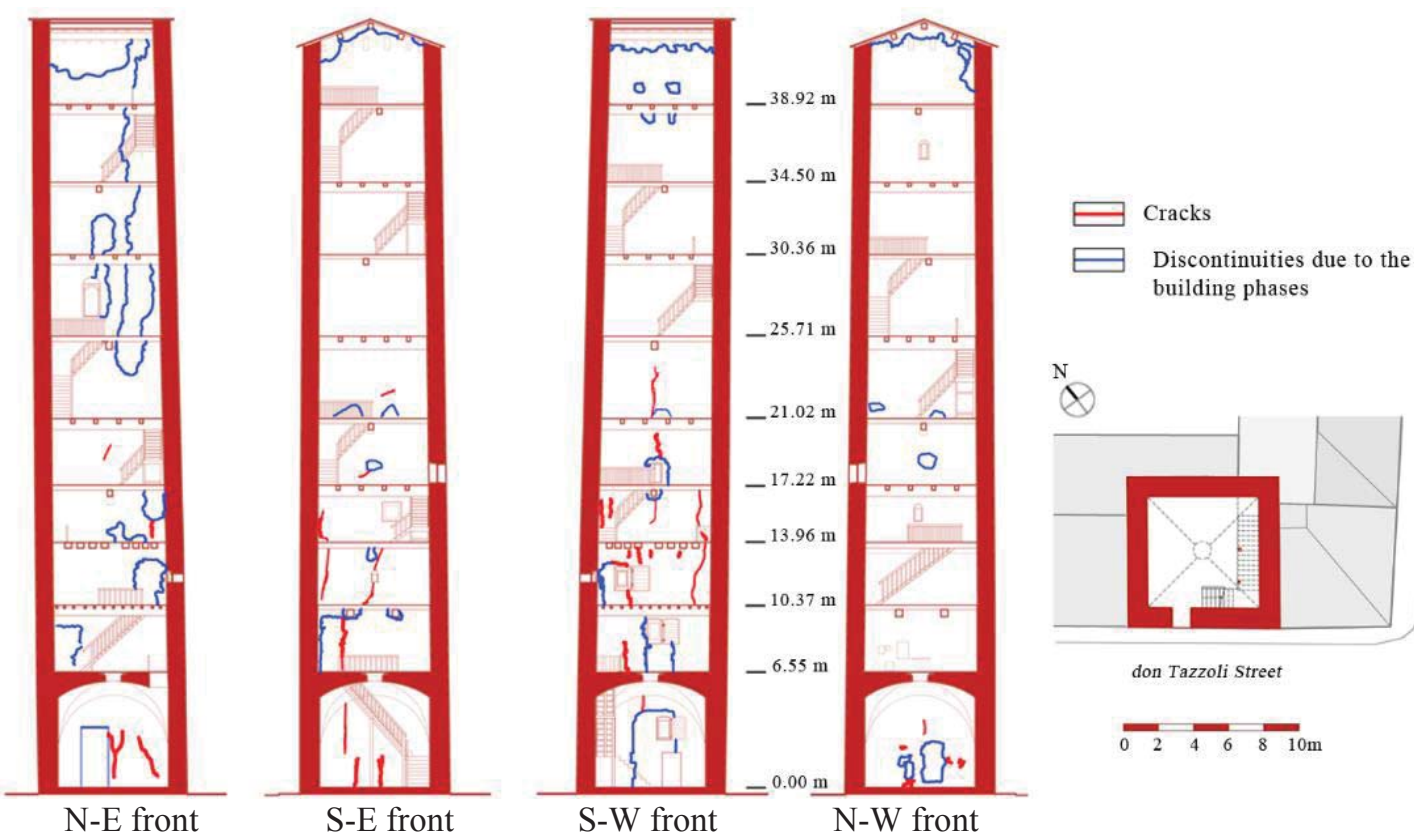

don Tazzoli Street

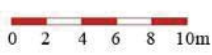

Figure 7: Section of the tower with the survey of the crack patterns and discontinuities due to different building phases.

\subsection{On-site inspections}

The accurate on-site inspections of the inner fronts of the tower are summarised in Fig. 7. From the stratigraphic survey, the discontinuities due to different building phases or local masonry reconstructions are identified. Furthermore, the on-site inspections highlighted the following aspects:

(a) Sharp discontinuities and deep cracks were found around the corner between the S-W and S-E walls (Fig. 6c) starting from the base up to $17.22 \mathrm{~m}$;

(b) Some deep and thick cracks were identified on the cross vault at the ground level;

(c) The presence of large areas with fragmentary and non-homogeneous masonry was identified starting from the height of $21.0 \mathrm{~m}$ on the N-E front (Fig. 7);

(d) Extended dark areas resulting from the fire of 1979 were found in the inner walls. 


\subsection{Dynamic characteristics of the tower}

Two series of AVTs were conducted on the tower involving a different number of sensors. The first test (4 measuring channels) was performed between October $23^{\text {rd }}$ and $24^{\text {th }}, 2016$ [6] with the twofold objective of identifying the vibration modes of the structure and evaluating the effectiveness of a 4-sensor setup for the future installation of a monitoring system. The second test (28 measuring channels) was performed between December $11^{\text {th }}$ and $12^{\text {th }}, 2017$ [5] with the objectives of obtaining a complete representation of the mode shapes and roughly assessing the impact of temperature changes on natural frequencies.

During the first test, 2 bi-axial seismometers (electro-dynamic velocity transducers, SARA SS45) were positioned at the opposite corners of the top floor to measure the dynamic response of the structure under ambient excitations. During the second test, high-sensitivity accelerometers (sensitivity of $10 \mathrm{~V} / \mathrm{g}$; peak acceleration of $0.5 \mathrm{~g}$ ) were employed to measure the response of the tower in 14 points belonging to 7 selected cross-sections (Fig. 8a).

The extraction of the modal parameters was performed with two well-known algorithms: the Frequency Domain Decomposition (FDD [8]) and the data-driven Stochastic Subspace Identification (SSI-data [9]). Both algorithms are available in the commercial software ARTeMIS [10]. Overall, 4 bending modes (B), 1 torsion mode (T) and 2 warping distortion modes $(\mathrm{W})$ were identified in the frequency range of $0-9 \mathrm{~Hz}$.

In the present paper only the results of the second test are reported and Fig. 8 summarises the modal parameters identified. The sequence of the first 5 modes is consistent with the results obtained in similar studies [3-4], whereas the last two modes appear to be very peculiar of the investigated structure. From the analysis of the identified dynamic characteristics, the following observations are drawn:

(a) Two closely spaced bending modes in opposite directions $\left(\mathrm{B}_{\mathrm{y} 1}\right.$ and $\left.\mathrm{B}_{\mathrm{x} 1}\right)$ are identified between 1.2 and $1.3 \mathrm{~Hz}$;

(b) The third mode is a global torsion mode $\left(\mathrm{T}_{1}\right)$ followed by other two higher-order bending modes $\left(\mathrm{B}_{\mathrm{y} 2}\right.$ and $\left.\mathrm{B}_{\mathrm{x} 2}\right)$;

(c) The last two modes $\left(\mathrm{W}_{1}\right.$ and $\left.\mathrm{W}_{2}\right)$ are associated with cross-section distortion of first and second order. The peculiar shape of these modes is known as warping.

(d) Regardless of the differences in the external temperatures, an excellent correspondence between the first 5 vibration modes was found while $\mathrm{W}_{1}$ and $\mathrm{W}_{2}$ exhibit a stronger sensitivity to the environmental conditions.

(a)

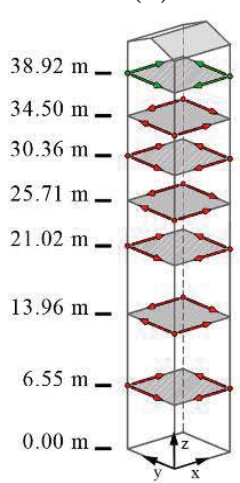

Mode no.

$f_{\mathrm{SSI}}(\mathrm{Hz})$ (b)

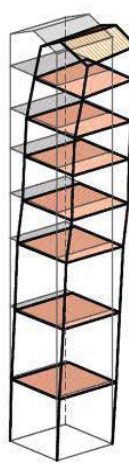

$\mathrm{B}_{\mathrm{y} 1}$

1.225 (c)

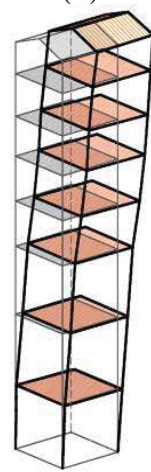

$\mathrm{B}_{\mathrm{x} 1}$

1.280 (d)

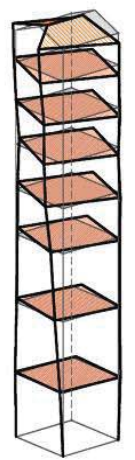

$\mathrm{T}_{1}$

4.095 (e)

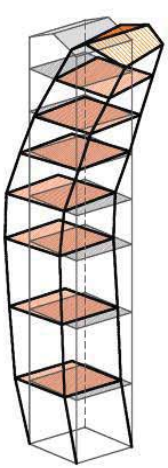

$\mathrm{B}_{\mathrm{y} 2}$

4.781 (f)

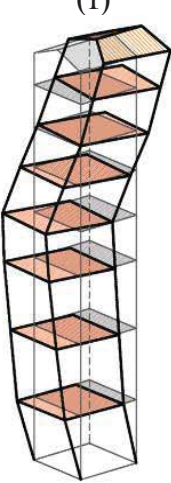

$\mathrm{B}_{\mathrm{x} 2}$

4.977 (g)

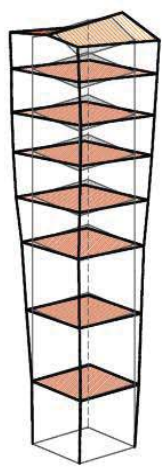

$\mathrm{W}_{1}$

5.504 (h)

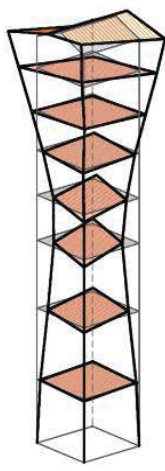

$\mathrm{W}_{2}$

7.465

Figure 8: (a) Sensors layout of the AVTs of 11-12 December 2017 ( $\left.\mathrm{T}=2.4^{\circ} \mathrm{C}\right)$; (b)-(h) Identified vibration modes. 


\section{THE ZUCCARO'S TOWER: FE MODELLING AND UPDATING}

The 3D model of the tower was developed with the FE code ABAQUS using the eightnode brick elements (C3D8). A relatively large number of elements were employed to obtain a regular distribution of masses, a good description of the opening distribution, and to avoid frequency sensitivity to mesh size. Overall, the numerical model consists of 10582 brick elements with 48438 degrees of freedom and an average mesh size of $0.5 \mathrm{~m}$ (Fig. 9a).

Once the geometry of the numerical model is established, the selection of the structural parameters to be updated is the next key issue. To prevent the ill-conditioning of the inverse problem and to improve the robustness of the updated parameter estimates the number of updating variables was kept smaller than the experimental parameters used as targets and only the uncertain structural parameters were updated. Consequently, the following assumptions were adopted: (a) the effect of soil-structure interaction was neglected, and the tower was assumed pinned at the base; (b) a linear elastic orthotropic material was adopted for the brick masonry, with constant mass density and Poisson's ratio equal to $17 \mathrm{kN} / \mathrm{m}^{3}$ and 0.15 respectively; (c) the shear modulus was considered equal to $G=\alpha \cdot E$, where $E$ is the Young's modulus, and $\alpha$ is a constant multiplier.

In addition, to calibrate all the identified vibrations modes, the following aspects were considered:

(a) the presence of the building aggregate was modelled with a uniform distribution of linear elastic translational springs with constants $k_{x}$ and $k_{y}$ on the S-E side and N-E side, respectively;

(b) the masonry walls were divided into 2 regions with constant material properties based on successive modelling refinement involving different assumptions on the model uncertainties (the full process is described in [6]);

(c) the presence of timber floors was simulated with a series of rigid beams connected to the vertical walls using linear elastic springs (constant $k_{R S}$ ).

Overall, the number of updating parameters was equal to 6: 2 Young's moduli, the ratio $\alpha$, and the springs constants $k_{x}, k_{y}$ and $k_{R S}$.

The adopted FEMU procedure was implemented in MATLAB environment and it is based on the Douglas-Reid method [11] with the Particle Swarm Optimisation (PSO) algorithm [12]: the updating parameters are iteratively corrected in a constrained range until a stable minimum solution for an objective function is found. Particularly, the following objective function was adopted:

$$
J(\boldsymbol{x})=\frac{100}{n} \sum_{i=1}^{n}\left|\frac{f_{i}^{A V T}-\hat{f}_{i}(\boldsymbol{x})}{f_{i}^{A V T}}\right|
$$

where $f_{\mathrm{i}}^{\mathrm{AVT}}$ is the $i$-th experimentally identified natural frequency and $f_{\mathrm{i}}(\boldsymbol{x})$ is the $i$-th polynomial approximation [11] of the numerical natural frequencies, expressed as functions of the $\boldsymbol{x}$ updating parameters.

Tab. 2 lists the optimal estimates of the uncertain parameters of the model. The difference between the elastic modulus of the upper and lower part of the tower is motivated by the presence of fragmentary and non-homogeneous masonry starting from the height of $21.0 \mathrm{~m}$ (Fig. 7).

In conclusion, an excellent correlation between the numerical and experimental modal parameters is obtained, with the maximum frequency discrepancy ( $\mathrm{DF}_{\max }$ ) being equal to $0.71 \%$. Hence, the updated model is capable of accurately representing the experimentally identified modal parameters. 


\begin{tabular}{lcccc}
\hline Mode no. & $f_{\text {SSI }}(\mathrm{Hz})$ & $f_{\text {FEM }}(\mathrm{Hz})$ & $D F_{i}[\%]$ & MAC \\
\hline $\mathrm{B}_{\mathrm{y} 1}$ & 1.225 & 1.226 & -0.08 & 0.98 \\
$\mathrm{~B}_{\mathrm{x} 1}$ & 1.280 & 1.279 & 0.08 & 0.98 \\
$\mathrm{~T}_{1}$ & 4.095 & 4.096 & -0.02 & 0.92 \\
$\mathrm{~B}_{\mathrm{y} 2}$ & 4.781 & 4.782 & -0.02 & 0.84 \\
$\mathrm{~B}_{\mathrm{x} 2}$ & 4.977 & 4.977 & 0.00 & 0.83 \\
$\mathrm{~W}_{1}$ & 5.504 & 5.504 & 0.00 & 0.88 \\
$\mathrm{~W}_{2}$ & 7.465 & 7.412 & 0.71 & 0.83 \\
\hline$D F_{\text {ave }}[\%]$ & - & - & 0.13 & - \\
$D F_{\max }[\%]$ & - & - & 0.71 & - \\
\hline
\end{tabular}

Table 1: Comparison between optimised and experimental (AVT 2017, $\mathrm{T}=2.4^{\circ} \mathrm{C}$ ) modal frequencies.

\begin{tabular}{lccc}
\hline Structural parameters & $\mathrm{X}_{\text {lower bound }}$ & $\mathrm{X}_{\text {optimal value }}$ & $\mathrm{X}_{\text {upper bound }}$ \\
\hline \hline$E_{L}(\mathrm{GPa})$ height $\leq 21.02 \mathrm{~m}$ & 2.68 & 3.08 & 3.62 \\
$E_{U}(\mathrm{GPa})$ height $>21.02 \mathrm{~m}$ & 1.48 & 1.73 & 2.00 \\
$\alpha$ & 0.315 & 0.335 & 0.349 \\
$G_{L}(\mathrm{GPa})$ height $\leq 21.02 \mathrm{~m}$ & 0.84 & 1.03 & 1.26 \\
$G_{U}(\mathrm{GPa})$ height $>21.02 \mathrm{~m}$ & 0.47 & 0.58 & 0.70 \\
$\Sigma k_{x}\left(\mathrm{kN} / \mathrm{m} \cdot 10^{5}\right)$ & 3.43 & 13.73 & 13.75 \\
$\Sigma k_{y}\left(\mathrm{kN} / \mathrm{m} \cdot 10^{5}\right)$ & 0.001 & 0.001 & 0.011 \\
$k_{R S}\left(\mathrm{kN} / \mathrm{m} \cdot 10^{5}\right)$ & 0.25 & 0.49 & 0.74 \\
\hline
\end{tabular}

Table 2: lower bound, optimised values and upper bounds of the identified structural parameters.

(a)

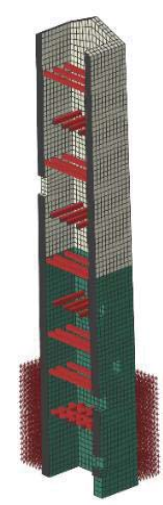

Mode no.

$f_{\mathrm{FEM}}(\mathrm{Hz})$ (b)

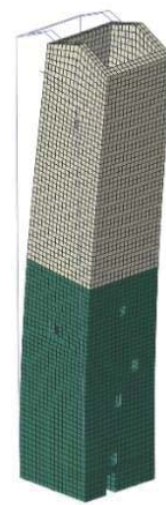

$\mathrm{B}_{\mathrm{y} 1}$

1.226 (c)

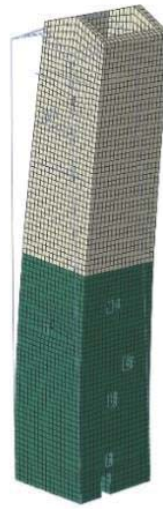

$\mathrm{B}_{\mathrm{x} 1}$

1.279 (d)

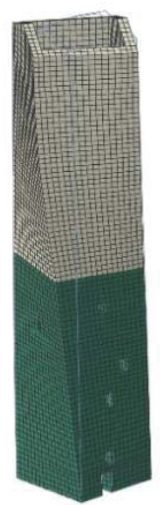

$\mathrm{T}_{1}$

4.096 (e)

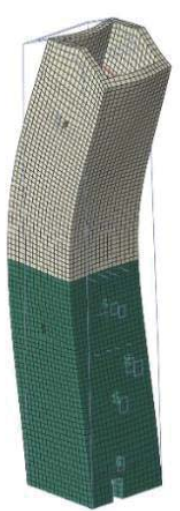

$\mathrm{B}_{\mathrm{y} 2}$

4.782 (f)

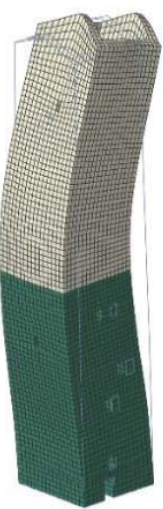

$\mathrm{B}_{\mathrm{x} 2}$

4.977 (g)

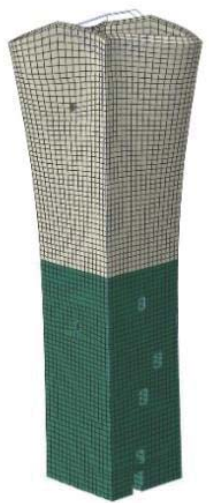

$\mathrm{W}_{1}$

5.504 (h)

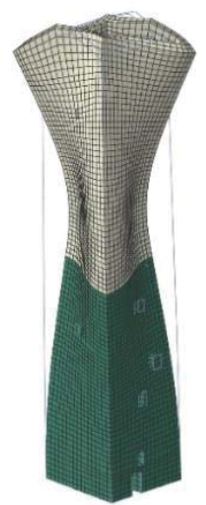

$\mathrm{W}_{2}$

7.412

Figure 9: (a) FE model of the Zuccaro's tower and (b-h) vibration modes of the optimal (updated) model. 


\section{THE ZUCCARO'S TOWER: APPLICATION OF THE DLRM APPROACH}

To test the capability of the proposed approach for the damage localisation in masonry towers, three damage scenarios (DS) were simulated, and pseudo-experimental monitoring data were generated for the Zuccaro's tower. The previously updated numerical model was divided into 80 elements (Figs. 10a-b) -8 elements per floor - to simulate the possible effect of local damages. Fig. 10 shows the selected elements, which belongs to different regions of the tower: lower (DS2), medium (DS44) and upper (DS74) parts.

The damages are simulated in a simplified way through a Young's modulus reduction by $30 \%$. Fig. 11 shows the changes in natural frequencies generated by the three simulated DS. The maximum variation is obtained for the DS2 and it is equal to $0.47 \%$ on the first mode $\left(\mathrm{B}_{\mathrm{y} 1}\right)$ while in the other two cases the maximum variations are lower than $0.25 \%$.

Since the installation of the monitoring system is ongoing, the monitoring data were generated from the experimentally identified natural frequencies. The environmental effects were not considered at this stage since the procedure is supposed to use the cleaned observations. Consequently, a normal distribution with a defined standard deviation was assumed for each frequency according to literature values (cleansed observations) [3].

Tab. 3 illustrates the adopted mean values and standard deviations for the pseudoexperimental monitoring data and reports the effects of the three DS on the 7 natural frequencies considered. It is worth noting that the DSs have comparable frequency shifts than the selected standard deviations (Tab. 3).

(a)

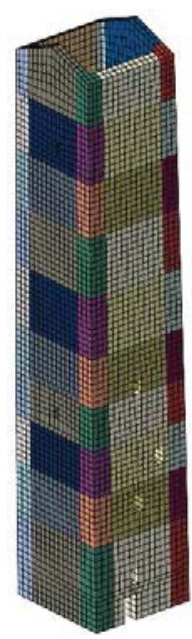

(b)

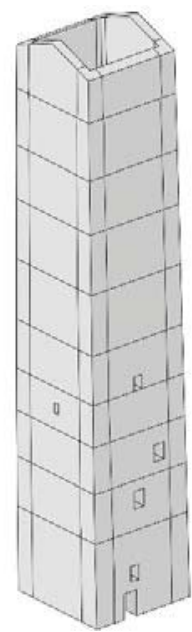

(c) DS2

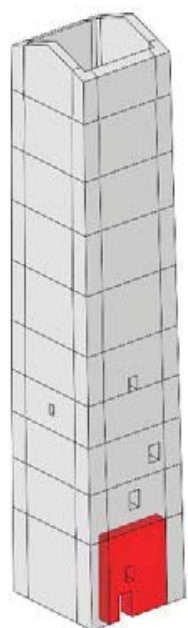

(d) DS44

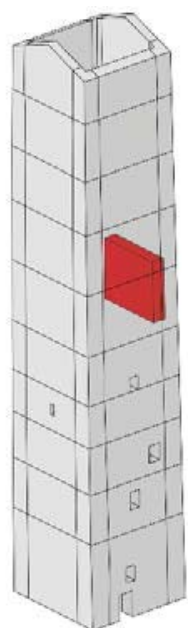

(e) DS74

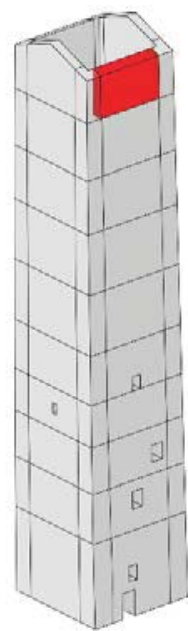

Figure 10: (a-b) FE model of the Zuccaro's tower divided into 80 elements; (c-e) simulated damage scenarios.

(a) DS2

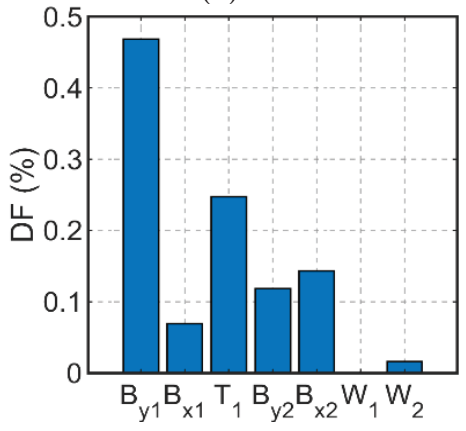

(b) DS44

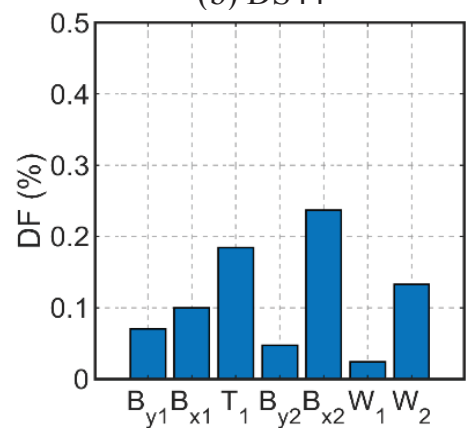

(c) DS74

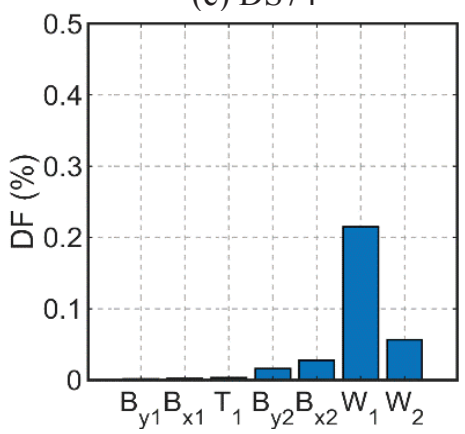

Figure 11: Comparison between the frequency shifts (DF, Eq. 1) of the three introduced damage scenarios. 


\begin{tabular}{lccccc}
\hline & $f_{\text {mean }}(\mathrm{Hz})$ & $\sigma_{f}(\mathrm{~Hz})$ & $\Delta f_{\mathrm{DS} 2}(\mathrm{~Hz})$ & $\Delta f_{\mathrm{DS} 44}(\mathrm{~Hz})$ & $\Delta f_{\mathrm{DS74}}(\mathrm{Hz})$ \\
\hline \hline $\mathrm{B}_{1 \mathrm{y}}$ & 1.225 & 0.005 & 0.006 & 0.001 & 0.000 \\
$\mathrm{~B}_{1 \mathrm{x}}$ & 1.280 & 0.005 & 0.001 & 0.001 & 0.000 \\
$\mathrm{~T}_{1}$ & 4.095 & 0.008 & 0.010 & 0.008 & 0.000 \\
$\mathrm{~B}_{2 \mathrm{y}}$ & 4.781 & 0.010 & 0.006 & 0.002 & 0.001 \\
$\mathrm{~B}_{2 \mathrm{x}}$ & 4.977 & 0.012 & 0.007 & 0.012 & 0.001 \\
$\mathrm{~W}_{1}$ & 5.504 & 0.020 & 0.000 & 0.001 & 0.012 \\
$\mathrm{~W}_{2}$ & 7.465 & 0.030 & 0.001 & 0.010 & 0.004 \\
\hline
\end{tabular}

Table 3: Statistic of the pseudo-experimental monitoring data with 3 simulated damage scenarios.

(a) DS2

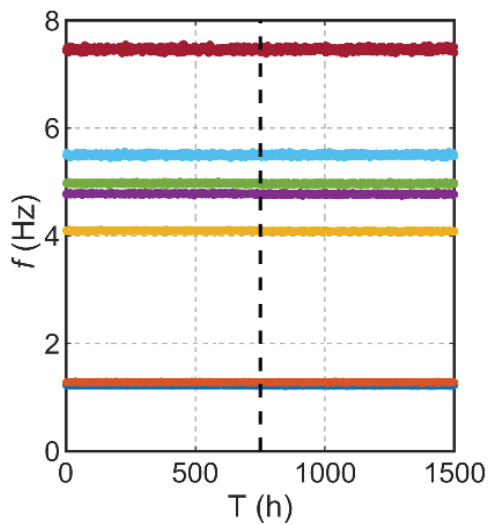

(d) $f_{1}(\mathrm{DS} 2)$

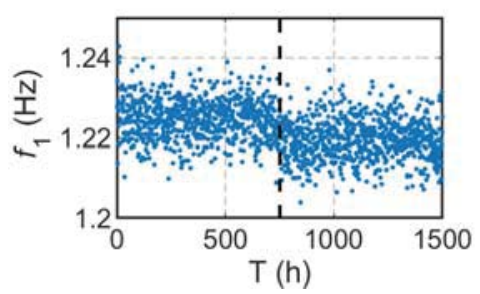

(b) DS44

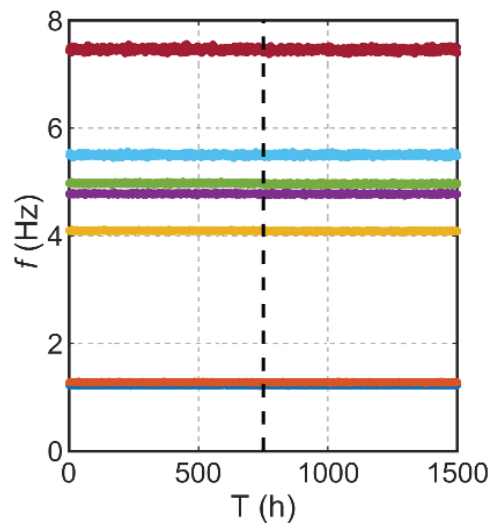

(e) $f_{5}(\mathrm{DS} 44)$

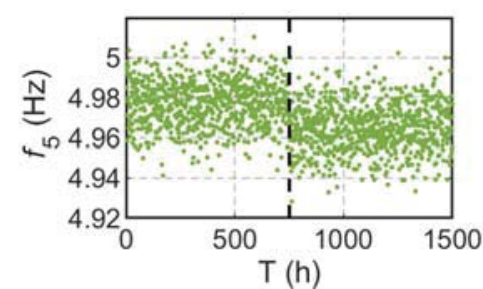

(c) DS74

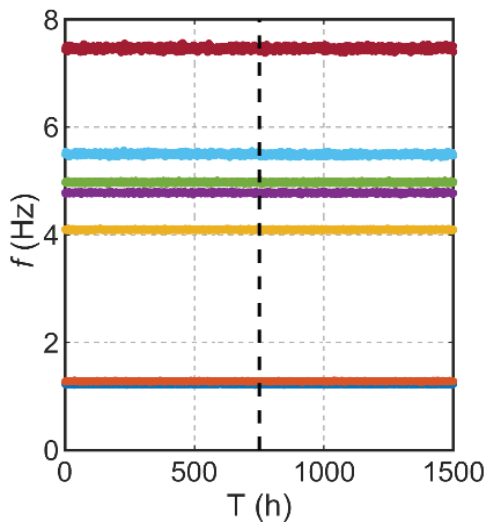

(f) $f_{6}(\mathrm{DS} 74)$

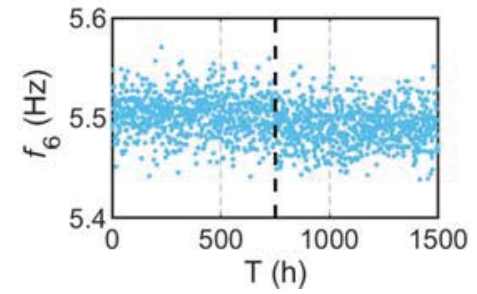

Figure 12: (a-c) Pseudo experimental monitoring data; (d-f) focus on the frequencies with the higher changes.

(a) DS2

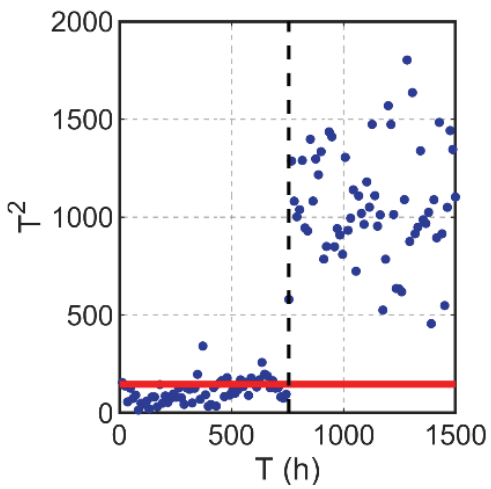

(b) DS44

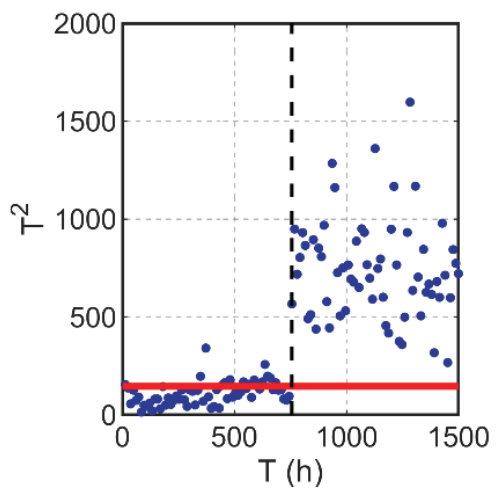

(c) DS74

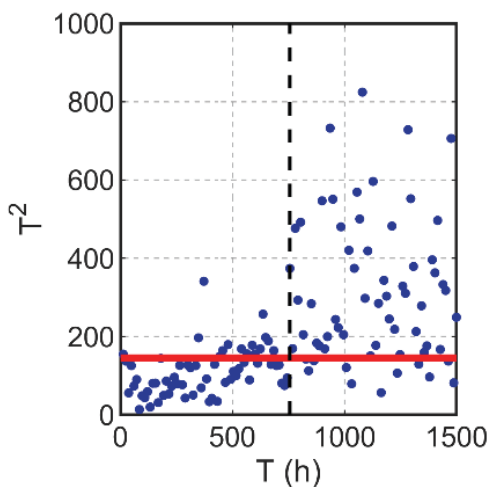

Figure 13: Damage detection through control charts for the 3 damage scenarios. 
Overall, 1500 observations are generated (1 observation per hour), and the simulated frequency shifts are introduced in the middle of the generated time history ( $T=750 \mathrm{~h}$; Fig. 12). The frequency shifts are particularly visible on the first mode $\left(\mathrm{B}_{\mathrm{y} 1}\right.$; Fig. $\left.12 \mathrm{~d}\right)$ for the DS2 and on the fifth mode $\left(\mathrm{B}_{\mathrm{x} 2}\right.$; Fig. 12e) for the DS44. Conversely, the effects of the DS74 on $f_{6}\left(\mathrm{~W}_{1}\right.$; Fig. 12f) are less evident; in this case, the standard deviation for the mode $\mathrm{W}_{1}$ is equal to 0.02 $\mathrm{Hz}$ while the considered frequency shift is equal to $0.01 \mathrm{~Hz}$.

To detect the presence of structural anomalies on the generated monitoring data, the control charts based on $\mathrm{T}^{2}$ - statistic are adopted [7]. A training period of $336 \mathrm{~h}$ (14 days) was employed to define the mean values of for the 7 natural frequencies. The residual errors between the mean frequencies of the reference period and the frequencies of each observation are used to define a multivariate control chart (Fig. 13) composed by subgroups of $12 \mathrm{~h}$. The structural anomalies are detected each time an observation lays outside the control limit. The black dashed line in Fig. 13 represents the instance in which the DSs were introduced. Clearly, the three DS are associated with different DFs (see Fig. 11) and consequently the outliers on the control charts are more evident in the DS2 (Fig 13a) where the DFs are higher while are less emphasised in the DS74 (Fig 13c) where the DFs are lower.

(a) DS2 (T=750h)

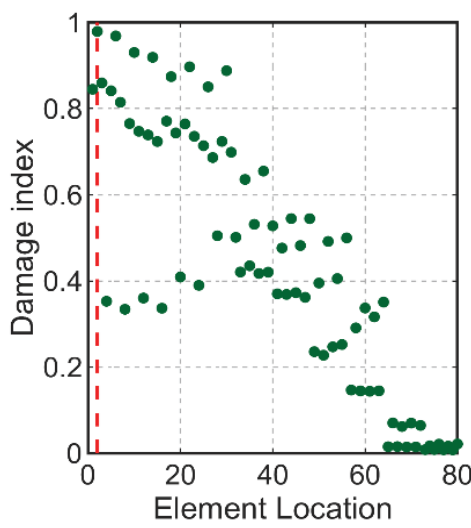

(b) DS44 (T=750h)

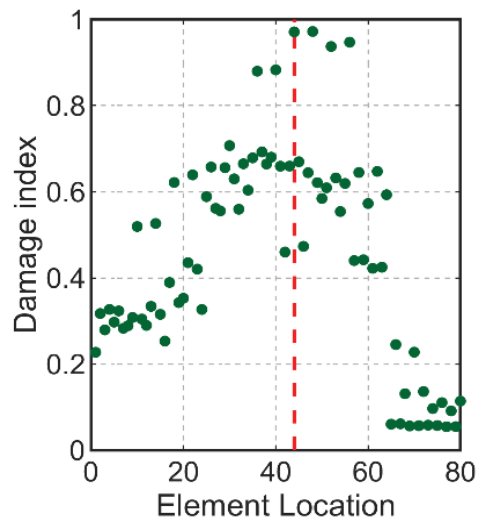

(c) DS74 (T=750h)

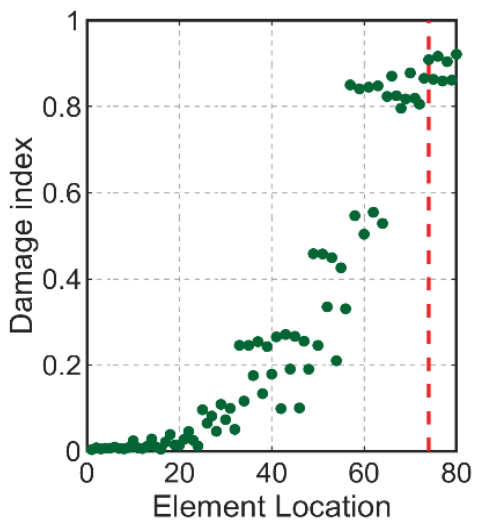

Figure 14: Damage localisation through the DLRM at the time T when the damage was introduced.

(a) DS2 (T=750h)

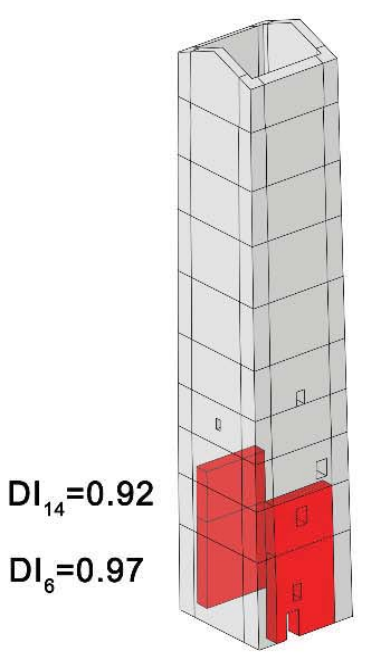

(b) DS44 (T=750h)

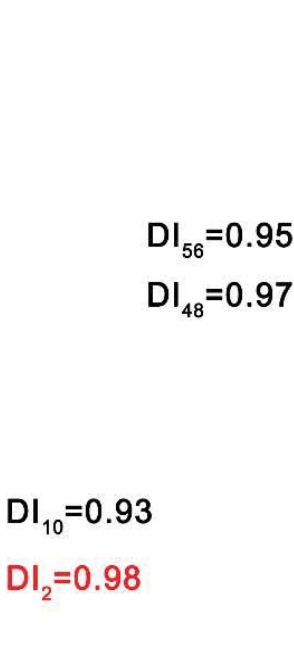

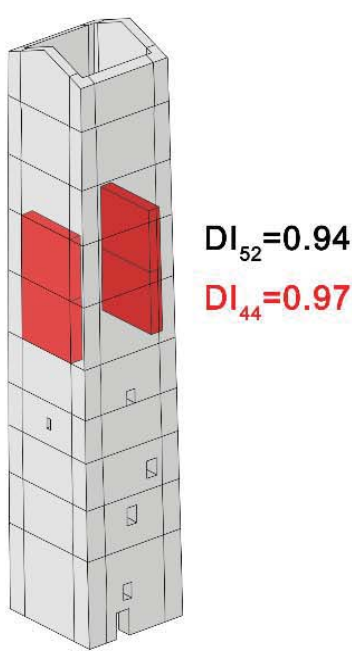

(c) DS74 (T=750h $)$
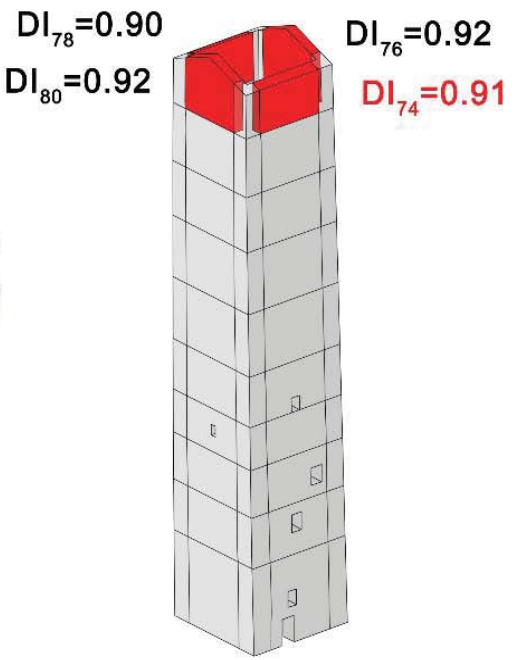

Figure 15: Elements with a damage index higher than 0.90 at the time $\mathrm{T}=750 \mathrm{~h}$ (the DI coloured in red indicates the correct position of the simulated damage). 
(a) DS2

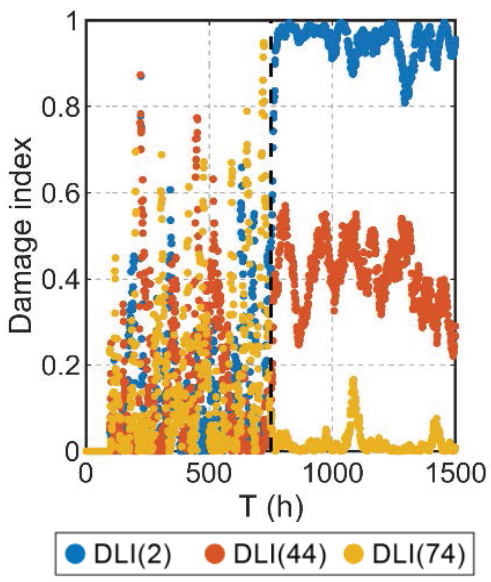

(b) DS44

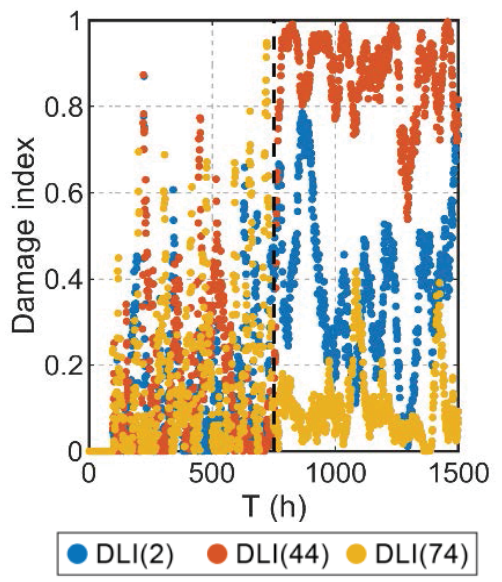

(c) DS74

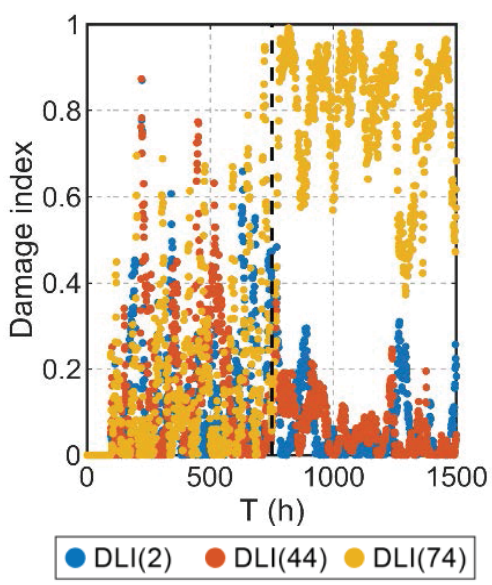

Figure 16: Comparison between the Damage Indexes of three elements over the entire monitoring period.

Once the onset of a damage is verified, the comparison between the pseudo-experimental frequency shifts and the computed DLRM is performed. The DLRM was previously generated from the updated FE model (Fig. 10a) following the procedure explained in Section 2 ; the adopted elastic modulus reduction was equal to the $50 \%$.

The comparison between the pseudo-experimental frequency shifts and the computed DLRM is provided by Eq. 3 and the results at time $T=750 \mathrm{~h}$ - that is the time when the damage is detected from the control charts - are depicted in Fig. 14. The red dashed line represents the correct damage location while the green dots are the Damage indexes (DIs) of each element. The elements with higher DIs are more likely to be damaged. As it was in the detection stage, the localisation is more evident for DS2 and DS44 since the DFs are higher.

Fig. 15 illustrates the position of the elements with a Damage index higher than 0.90 . The following observations can be drawn: (a) the DS2 is correctly localised in the lower part of the tower on the walls along the x-direction; (b) similarly, the DS44 is correctly localised among the $5^{\text {th }}$ and $7^{\text {th }}$ floors on the walls along the y-direction; (c) the DS74 is correctly localised in the top floor of the tower, but it was not possible to distinguish on which wall. Particularly, the localisation of the last DS relies on the induced frequency shift on mode $\mathrm{W}_{1}$ (see Fig. 11c), which is associated with a cross-sectional distortion. Conversely, the other localisations rely also on bending modes (see Figs. 11a-b) which are characterised by a direction-dominated component of motion.

In conclusion, Fig. 16 illustrates the evolution over time of the DIs of three selected elements. Before the introduction of the structural anomaly at $T=750 \mathrm{~h}$, the DIs are characterised by random variations; conversely, when the damage occurs, the DIs exhibit a much stable pattern. Notably, the stability is correlated with the magnitude of the frequency shift: bigger for DS2 and lower of DS74.

\section{CONCLUSIONS}

Prior research has demonstrated the effectiveness of damage localisation for masonry towers based on monitored frequency data and FE modelling [3-4]. In this study, further investigations are carried out to increase the capability of an accurate real-time damage evaluation. Accordingly, a model-based damage localisation procedure using previously computed damage scenarios and continuously identified natural frequencies is illustrated. The proposed approach is exemplified on the Zuccaro's tower; an ancient masonry structure built in the Middle Ages in the city of Mantua, Italy 
The results from the investigated structure suggest the following conclusions:

1) In masonry towers, and generally in slender structures, the mutual variation of natural frequencies caused by a structural damage is directly correlated with the damage location;

2) The simulated frequency shifts added to the pseudo-experimental monitoring data were detected and localised with the proposed approach;

3) A cost-effective monitoring setup composed by few sensors placed at the top of the structure and combined with an automated modal identification algorithm and a regression model to filter out the environmental effects can be used not only to detect but also to localise a structural damage.

Promising results suggest future applications of the methodology for monitoring real structures. To expand the capability of the proposed approach, further investigations with multiple damage scenarios should be performed.

\section{ACKNOWLEDGEMENTS}

Sincere thanks are due to M. Cucchi (LPMSC, Politecnico di Milano) and A. Ruccolo (PhD candidate, Politecnico di Milano) who assisted the authors in conducting the field tests.

\section{REFERENCES}

[1] C. Gentile, M. Guidobaldi, A. Saisi, One-year dynamic monitoring of a historic tower: damage detection under changing environment, Meccanica 51(11), 2873-2889, 2016.

[2] R. M. Azzara, G. De Roeck, M. Girardi, C. Padovani, D. Pellegrini, E. Reynders, The influence of environmental parameters on the dynamic behaviour of the San Frediano bell tower in Lucca, Engineering Structures 156, 175-187, 2018.

[3] A. Cabboi, C. Gentile, A. Saisi, From continuous vibration monitoring to FEM-based damage assessment: Application on a stone-masonry tower. Construction and Building Materials 156, 252-265, 2017.

[4] F. Ubertini, N. Cavalagli, A. Kita, G. Comanducci, Assessment of a monumental masonry bell-tower after 2016 central Italy seismic sequence by long-term SHM, Bulletin of Earthquake Engineering 16(2), 775-801, 2018.

[5] A. Saisi, S. Terenzoni, A. Ruccolo, C. Gentile, Safety of the Architectural Heritage: Structural Assessment of the Zuccaro's Tower in Mantua, in: RILEM Bookseries 18, 2422-2430, 2019.

[6] C. Gentile, A. Saisi, P. Borlenghi, FE modelling for seismic assessment of an ancient tower from ambient vibration survey, in: Proceedings of the 8th IOMAC - International Operational Modal Analysis Conference, 295-305, 2019.

[7] H. Hotelling, Multivariate quality control-illustrated by the air testing of sample bombsights, in Techniques of Statistical Analysis, 111-184, 1947.

[8] R. Brincker, L. Zhang, P. Andersen, Modal identification of output-only systems using frequency domain decomposition. Smart Material and Structures 10(3), 441-445, 2001. 
[9] B. Peeters, System identification and damage detection in civil engineering. Ph.D. Thesis, Katholieke Universiteit Leuven, Belgium, 2000.

[10] Structural Vibration Solutions (SVS). ARTeMIS Extractor 2010. Aalborg, Denmark, 2010.

[11] B. M. Douglas, W. H. Reid, Dynamic tests and system identification of bridges. Journal of the Structural Division ASCE 108(10), 2295-2312, 1982.

[12] J. Kennedy, R. Eberhart, Particle Swarm Optimization, in: Proceedings of IEEE International Conference on Neural Networks, 1942-1948, 1995. 